\title{
Extending LCA Methodology for Assessing Liquid Biofuels by Phosphate Resource Depletion and Attributional Land Use/ Land Use Change
}

\author{
Heiko Keller, Horst Fehrenbach, Nils Rettenmaier, and Marie Hemmen
}

\begin{abstract}
Many pathways towards reaching defossilization goals build on a substantially increased production of bio-based products and energy carriers including liquid biofuels. This is, amongst others, limited by land and phosphorous availability. However, it is challenging to adequately capture these limitations in LCA using state-of-the-art LCI and LCIA methods. We propose two new methods to overcome these challenges: (1) attributional land use and land use change (aLULUC) evenly attributes LU-/LUC-related burdens (emissions) occurring in a country to each hectare of cropland used in that country and (2) phosphate rock demand as a standalone resource indicator for a finite resource that cannot be replaced. Approach, calculations and used factors are described for both methods, and exemplary results for biofuels are presented. We conclude that both methods can yield additional insight and can support finding solutions for current challenges in agriculture.
\end{abstract}

\section{Introduction}

As for most bio-based products, replacing fossil fuels by biofuels mostly creates environmental advantages and disadvantages at the same time. Advantages typically relate to climate change mitigation and savings of fossil energy resources, and disadvantages of various kinds are usually caused by the required biomass production. This well-known pattern is reflected in standard LCA results in the field.

Public and scientific discussions more and more focus on environmental burdens and limitations of agriculture that are becoming important bottlenecks of agriculture on a global scale. These aspects include land use/biodiversity, water and increasingly also limited phosphate resources. These could also become limiting for currently discussed pathways for defossilization of the society, which often builds on using more bio-based products in general and biofuels of various kinds in particular.

H. Keller $(\bowtie) \cdot$ H. Fehrenbach $\cdot$ N. Rettenmaier $\cdot$ M. Hemmen ifeu - Institute for Energy and Environmental Research Heidelberg, Heidelberg, Germany e-mail: Heiko.Keller@ifeu.de 
Results of state-of-the-art LCAs however often do not effectively support finding new solutions in these areas for various reasons. This paper focusses on the aspects land use/land use change (LUC) and phosphate resources. In the following chapters, limitations of current state-of-the-art LCA methods are discussed, and two new methods are proposed as solutions: (1) attributional land use and land use (aLULUC) change as new alternative to dLUC/iLUC and (2) phosphate rock demand as new stand-alone resource indicator.

\section{Attributional Land Use and Land Use Change}

\subsection{Background}

Land use change (LUC) describes the relative change in the use or management of an area compared to a previous use of the same area and the associated emissions (or emission avoidance). Which methodology is suitable for the quantification LUC-related burdens depends on the goal and scope of a study. This can include the overall greenhouse gas balance of a country, the traceable direct consequences of a specific product in its supply chain (dLUC, direct land use change) or the indirect consequences of a change in the market, e.g. triggered by the support of a specific product such as biofuels (iLUC, indirect land use change).

In theory, dLUC could accurately determine the actual LUC emissions from a product such as rapeseed diesel. However, this is not applicable in practice for several reasons: Firstly, existing data is not available and subject to data protection. Secondly, more biomass not associated with land use change is available than interested customers or regulated markets are demanding. Thus, dLUC is not useful to mitigate or stop continuing land use change.

iLUC factors are calculated by combining land use models with an economic equilibrium or partial system and are intended to estimate the overall impact of a targeted or shock-like increase in production on global land use. Fehrenbach [18], amongst others, analysed and described the wide range of results depending on the choice of model. The iLUC approach is therefore only of limited use for developing solutions based on life cycle assessments due to the disagreement amongst experts about the suitability and reliability of the various iLUC models. Moreover, iLUC always describes results of changes or measures, which is incompatible with attributional LCAs describing the status quo. Finkbeiner [19] also discussed these aspects in detail.

We propose a life cycle inventory approach termed attributional land use/land use change (aLULUC) to attribute existing and documented burdens caused by land use change and continuous burdens/emissions from using converted land to products [1]. Here we focus on climate impacts although further impact categories such as biodiversity [2,3] can also be assessed using the life cycle inventory method aLULUC. 


\subsection{Approach}

A decisive premise for aLULUC is that land use changes to arable land take place in reality. These land use changes are usually recorded and associated emissions are backed up with data. This includes one-time emissions from actual LUC and continuous emissions mainly from organic soils caused by LUC but occurring for many decades of land use (LU) that can only be stopped if land use is given up and appropriate protection measures are taken.

The aLULUC concept is independent of models of future land use change as it is the case for iLUC. In the same systematic way as real emissions are attributed to the processes of a life cycle, real LUC processes can be attributed to the associated processes, as it is also done applying the dLUC concept. However, even if actual land use changes can be clearly assigned to certain agricultural products, all agricultural products of a production area compete for limited availabilities on the local market for cropland. The reaction of the markets on, e.g. the EU biofuels policy, has shown that crops on and products from recently logged land (or from "LUC-free" land) can be flexibly allocated to customers according to their preferences. For that reason, a land-market-based attribution of aLULUC to products produced on that land following the aLULUC concept is a more consistent representation of the underlying processes than a direct attribution following the dLUC concept. For the majority of agricultural products, country borders are the most appropriate geographical reference areas for the aLULUC concept. Firstly, there are no internal trade barriers within national markets. More importantly, however, decisions and policies regarding the conservation of areas such as rainforests, wetlands and grasslands are made or influenced at the country level. A more specific attribution of LUC to individual crops within these markets would require economic assumptions and models that seek to establish causalities. These do not necessarily reflect the complex socio-economic and political processes that can cause, promote or prevent LUC.

Following the proposed aLULUC approach, the real land use changes that have been caused by agriculture (of a defined region) are allocated to all agricultural products in proportion to the land requirements. It is therefore an allocation according to the attribute land demand. aLULUC can be calculated for arable land as well as for other types of land such as grassland. The country- and year-specific aLULUC factor for arable land is determined as follows: All carbon stock changes in biomass and soils caused by net conversion from other types of land use to arable land in a country in a certain year are summed up and divided by the area of arable land used in that year. One-time changes in biomass and soil carbon stocks (LUC) are attributed to the year in which the LUC occurs although actual $\mathrm{CO}_{2}$ emissions may be partially delayed by a few years. Continuous emissions of $\mathrm{CO}_{2}, \mathrm{CH}_{4}$ and $\mathrm{N}_{2} \mathrm{O}$ from the cultivation of organic soils (LU) are counted in the year in which they occur. Averages of aLULUC factors over the last ten available years result in stable values that do not disregard medium- to long-term developments. Detailed calculation procedures and data sources are discussed in [1]. Current emission factors for 
the climate impact of land use and land use change according to the aLULUC concept for selected countries can be found in Table 1.

\subsection{Application Example: GHG Emissions Including aLULUC of European Rapeseed Biodiesel}

Biodiesel can achieve certain climate change mitigation if it replaces conventional diesel. This is however only the case if land use does not cause high additional greenhouse gas emissions. Usually, this problem is discussed for palm oil biodiesel and deforestation. However, depending on the used land and the methodological approach used to attribute emissions from LU and LUC to the fuel, also European rapeseed biodiesel can cause in total more greenhouse gas emissions than it saves (Fig. 1). Greenhouse gas emissions from LU and LUC in Europe mainly stem from conversion of grassland and from cultivation on organic soils, i.e. drained wetlands/ peatland.

The cultivation of rapeseed on former grassland can lead to overall additional contributions to climate change following the dLUC approach if common time horizons of up to about 25 years are used. If organic soils/peatlands are used, an analogous direct attribution of LU to the product (termed dLU in the figure) could even lead to very high additional greenhouse gas emissions. Where such emissions have

Table 1 Exemplary country-specific aLULUC emission factors for annual crops cultivated on arable land selected from [1]

\begin{tabular}{l|c|l|l}
\hline Country & $\begin{array}{l}\text { Total aLULUC } \\
\mathrm{t} \mathrm{CO}_{2} \text { eq/(ha year) }\end{array}$ & $\begin{array}{l}\mathrm{aLU} \\
\mathrm{t} \mathrm{CO}_{2} \mathrm{eq} /(\text { ha year) }\end{array}$ & $\begin{array}{l}\mathrm{aLUC} \\
\mathrm{t} \mathrm{CO}_{2} /(\text { ha year })\end{array}$ \\
\hline France & 0.90 & 0.41 & 0.50 \\
\hline Germany & 1.44 & 1.22 & 0.21 \\
\hline Italy & 0.26 & 0.14 & 0.12 \\
\hline Netherlands & 4.50 & 4.08 & 0.41 \\
\hline Poland & 1.60 & 1.59 & 0.01 \\
\hline Romania & 0.17 & 0.14 & 0.03 \\
\hline Spain & 0.04 & 0.04 & 0.01 \\
\hline United Kingdom & 0.55 & 0.55 & 0.00 \\
\hline EU 28 & 1.05 & 0.85 & 0.20 \\
\hline Argentina & 3.36 & 0.03 & 3.33 \\
\hline Colombia & 52.3 & 0.00 & 52.3 \\
\hline Brazil & 9.32 & 0.00 & 9.32 \\
\hline Malaysia & 55.4 & 42.9 & 12.5 \\
\hline Indonesia & 30.4 & 13.7 & 16.7 \\
\hline India & 0.06 & 0.06 & 0.00 \\
\hline Russia & 0.80 & 0.30 & 0.50 \\
\hline USA & 0.52 & 0.52 & 0.00 \\
\hline
\end{tabular}




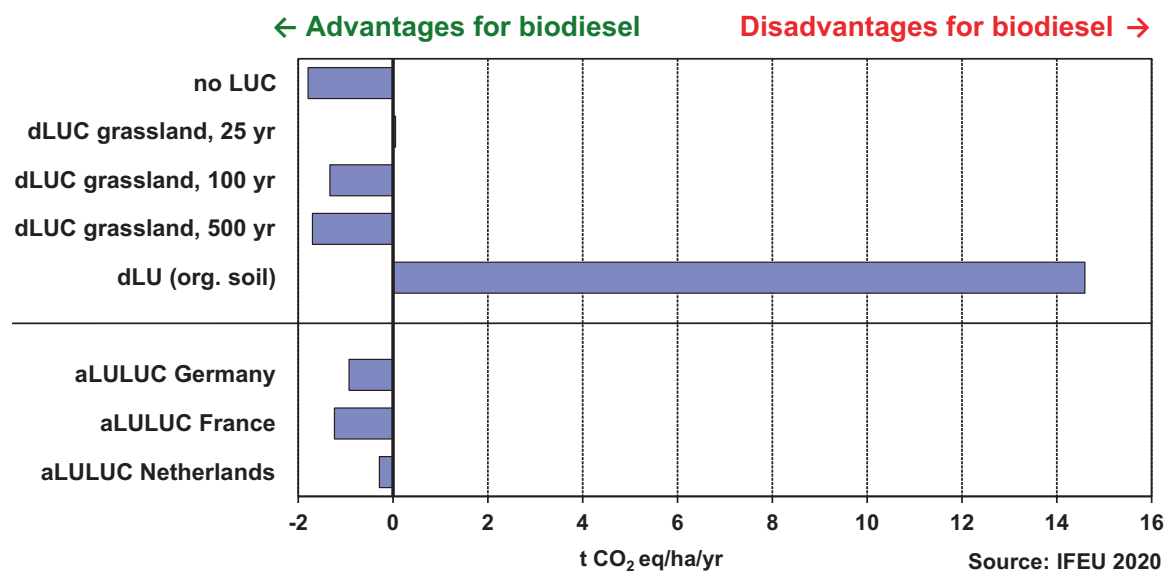

Fig. 1 Life cycle greenhouse gas emissions of European rapeseed biodiesel compared to conventional diesel. All results are based on the same life cycle comparison with differences only in the used land and the methodological approach to land use (LU) and land use change (LUC). The time horizons, over which one-time emissions are distributed, are specified where applicable

to be attributed to a fuel according to the European renewable energy directive [4], no farmer would of course cultivate crops for biofuels. Nevertheless, biofuel crops occupy land and increase the pressure to use former grassland and peatland for cultivation of crops in general. Following the aLULUC approach, LU- and LUCrelated emissions are evenly distributed over all cropland of the respective country. This leads to somewhat reduced climate change mitigation for French rapeseed biodiesel. Especially emissions from cultivated organic soils in Germany and even more so in the Netherlands lead to a substantial reduction of greenhouse gas emission savings.

This application example shows that LU and LUC can make significant contributions to carbon footprints also in European countries. The aLULUC approach helps that these emissions are not neglected because direct attribution of these emissions to products does not take place in practice - neither in Europe nor overseas. Hardly anybody would, for example, consider that, e.g. his/her meat could stem from animals raised on corn grown on drained Northern European peatland.

\section{Phosphate Rock Demand}

\subsection{Background}

Phosphate rock is the basic raw material for the production of phosphoric acid, which is essential for the production of phosphate products such as fertilizers, animal feed, food and other industrial products. Ninety per cent of the global supply of 
phosphate is used as fertilizer in agriculture [5]. Eighty-five per cent of phosphate ore is extracted from marine sedimentary deposits and 15\% from magmatic deposits, with phosphate ore chemically including iron and aluminium salts as hydrate complexes with very different phosphorous and phosphate contents. Deposits based on guano deposits are largely exhausted [6]. The main producing countries are currently China (52\%), the USA (10\%) and Morocco (12\%) [7]. Marketable rock phosphate contains between $27 \%$ and $40 \%$ phosphate ([8] cited in [6]). Besides, recycled phosphate can be recovered from sewage sludge by several processes $[9,10]$.

As a mineral raw material, phosphate is a non-renewable resource. Depending on the source, the static lifetime of global phosphate reserves is only several decades to a few centuries [11-14] (see Fig. 2).

This shortage is further worsened by a growing world population and simultaneously changing consumption patterns [15], resulting in an increasing demand for phosphate.

Due to this growing importance, the impossibility of substitution by other raw materials in central applications and simultaneous limitation, we recommend integrating the resource "phosphate" in life cycle assessments using a separate indicator. We suggest using the indicator phosphate rock demand as proposed in [16] and presented below.

\subsection{Approach}

Various indicators can be used in LCA to address resource use. One indicator is the cumulative raw material demand (CRD), which is defined as the sum of all raw materials entering a system - except water and air - expressed in mass units. Other indicators also include weighting of the individual raw materials by, e.g. scarcity. These established indicators have in common that the mineral resource consumption of phosphate is not reported separately. This is not sufficient especially for LCAs with a strong focus on agriculture such as LCAs on biofuels because phosphate/phosphorus is a raw material that cannot be replaced by any other element in

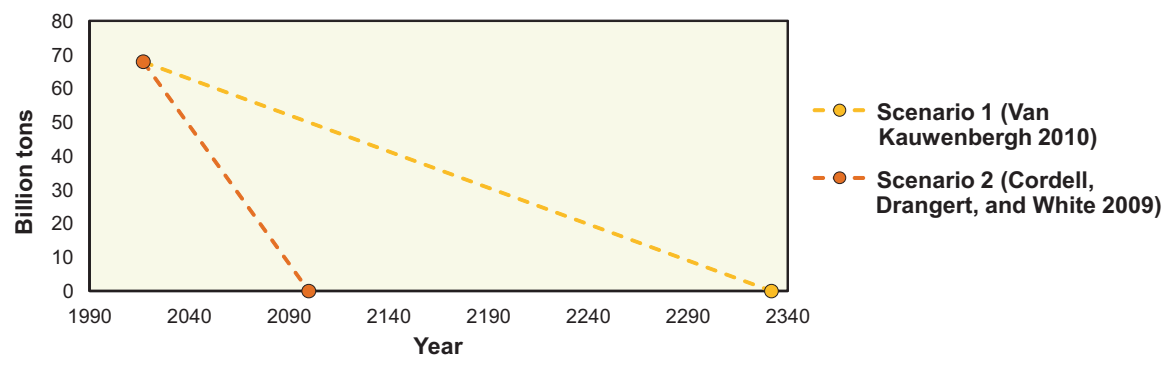

Fig. 2 Range of scenarios on the static lifetime of global phosphate reserves 
its main application as a fertilizer. Therefore, the consumption of non-renewable phosphate rock needs to be addressed independently from other raw materials.

We propose a new indicator phosphate rock demand (informally also "phosphate rock footprint") following the concept of the CRD but only including phosphate rock. Phosphate rock demand is determined by the initial rock mass. The recommended unit for the life cycle inventory is "phosphate rock standard" [16]. The definition of a standard is necessary because phosphate rock can have significantly different phosphate contents. Based on [17], an average content of $25 \%$ of $\mathrm{P}_{2} \mathrm{O}_{5}$ is set for phosphate rock standard. $\mathrm{P}_{2} \mathrm{O}_{5}$ is the reference substance/unit commonly used in agriculture. This corresponds to $32 \%$ raw phosphate. This means that $1 \mathrm{~kg}$ of mineral $\mathrm{P}_{2} \mathrm{O}_{5}$ fertilizer corresponds to $4.0 \mathrm{~kg}$ of phosphate rock (std.) or $3.125 \mathrm{~kg}$ of raw phosphate (std.). This specification explicitly refers to mineral fertilizers. For organic fertilizers, a specific procedure must be derived depending on the goal and scope of the study. If consequential modelling is applied, for example, additional phosphate sources are taken into account, which can replace mineral phosphate without restrictions and which are available in limited quantities during the reference period of the study.

Results can be normalized to inhabitant equivalents by dividing them by the average annual resource consumption per inhabitant. The following normalization factors were derived for this purpose ([16] for details):

- For the reference area Germany: $16.1 \mathrm{~kg}$ phosphate rock (std.)/(inhabitant • year).

- For the reference area Europe: $23.1 \mathrm{~kg}$ phosphate rock (std.)/(inhabitant • year).

These factors refer to the 5-year average and thus remove short-term fluctuations in the statistics. Normalization factors for other regions can be derived accordingly.

\subsection{Application Example: Phosphate Rock Demand of Different Biofuels}

With the approach described in Chap. 3.2 outlining the definition and calculation of the indicator "phosphate rock demand", the resource phosphate can be integrated into life cycle assessments. In the following, the application of this approach is explained using an illustrative example. Several bio-based fuels were analysed: bioethanol, biomethane, biodiesel, fuel from vegetable oil and Fischer-Tropsch diesel. Figure 3 shows the ranges between minimum and maximum phosphate rock demand per biofuel.

The phosphate rock demand of different biofuels differs significantly. Firstgeneration biofuels tend to perform much better than second-generation bioethanols with respect to phosphate rock depletion. Results also depend heavily on the biofuels' production schemes, co-product uses and their local conditions. This striking difference between first- and second-generation bioethanols mainly results from phosphate inputs into fermentation processes without subsequent productive 
Disadvantages for biofuel $\rightarrow$

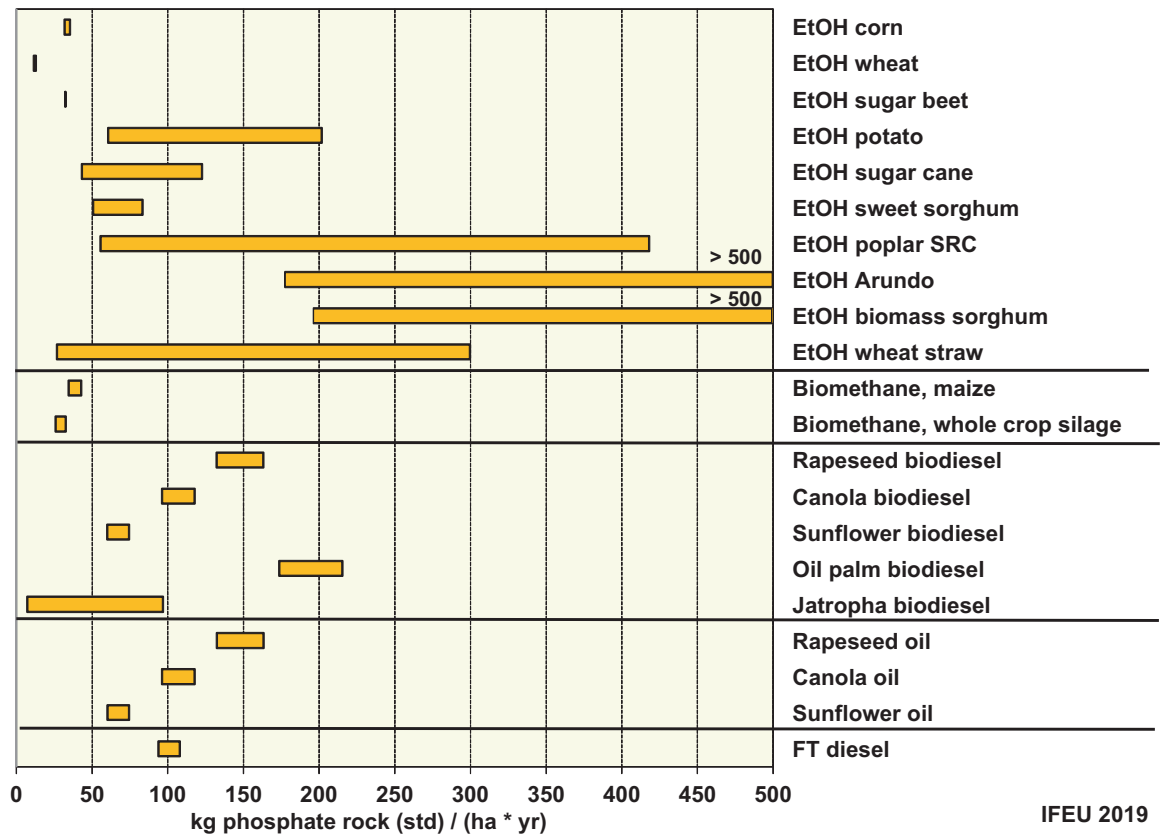

Fig. 3 Phosphate rock demand of different biofuels compared to the respective conventional fossil fuel. The ranges encompass conservatively and optimistically estimated phosphate rock demands for each fuel. EtOH stands for bioethanol, SRC for short rotation coppice and FT for Fischer-Tropsch

recovery. Based on the large range of results, it seems plausible that this aspect has not been optimized or not even been recognized as potential problem in the current state of process development and maturation. This underlines the importance of the indicator phosphate rock demand to support finding solutions to the problem of declining non-renewable phosphate resources.

\section{Conclusions}

In this paper, we presented two LCA extensions that intend to better address limitations of current agriculture in decision-making processes.

The life cycle inventory method attributional land use and land use change (aLULUC) evenly attributes impacts of deforestation, grassland conversion (both LUC) and organic soil use (LU) actually taking place in a country to each hectare of cropland used in that country. This has several advantages over commonly used dLUC or iLUC: 
- Firstly, aLULUC is based on available data and does not require complex economic models or value-based choices of crucial parameters such as time horizons. This makes results more robust.

- Secondly, a comprehensive and regularly updated database is available based on the respective national inventory reports and FAOSTAT for LUC and LU.

- Thirdly, in contrast to iLUC, aLULUC is compatible to attributional LCA, because it attributes burdens/emissions to products and not to change processes. Finally, aLULUC factors on a country level can help to derive meaningful messages to politicians in charge for protection measures or to consumers.

The LCIA indicator phosphate rock demand was introduced as a stand-alone resource indicator because phosphate is a finite resource that cannot be replaced in its vital major application as fertilizer. Thus, phosphate consumption without recycling needs to be reduced which requires measures that are independent of other finite resources. The phosphate rock footprint was shown to be a valuable tool to identify such measures. For biofuels, for example, hot spots of phosphate use were found in various life cycle stages. This information can easily be lost in common evaluations of common aggregate resource indicators.

In summary, the LCI/LCIA methods aLULUC and phosphate rock demand are suitable to derive additional insights and recommendations for LCAs with a wide range of goals and scopes. In particular, both methods are designed to yield recommendations how to overcome crucial bottlenecks of agriculture that are solutionoriented and useful in practice. Therefore, these methods should be considered as an extension of or, if already addressed, alternative to methods nowadays routinely applied in LCA.

Acknowledgements A joint effort in several projects led to this work. The projects have received funding from the European Union's Horizon 2020 research and innovation programme under grant agreement Nos. 727698 ("Magic"), 763911 ("eForFuel") and 727463 ("BioMates") as well as from the Bio-Based Industries Joint Undertaking (JU) under grant agreement No. 792004 ("UNRAVEL"). The JU receives support from the European Union's Horizon 2020 research and innovation programme and the Bio-Based Industries Consortium. Furthermore, the authors would like to thank all colleagues at ifeu, in particular Guido Reinhardt, Regine Vogt and Nabil Abdalla, for their contributions, discussions and recommendations in developing the LCA methods discussed in this paper.

\section{References}

1. Fehrenbach, H., Keller, H., Abdalla, N., \& Rettenmaier, N. (2020). Attributional land use $(a L U)$ and attributional land use change (aLUC) - A new method to address land use and land use change in life cycle assessments, version 2.1 of ifeu paper 03/2018. Available at www.ifeu. de/en/ifeu-papers/. ifeu - Institute for Energy and Environmental Research Heidelberg.

2. Fehrenbach, H., Grahl, B., Giegrich, J., \& Busch, M. (2015). Hemeroby as an impact category indicator for the integration of land use into life cycle (impact) assessment. International Journal of Life Cycle Assessment, 20(11), 1511-1527. 
3. Lindner, J. P., Fehrenbach, H., Winter, L., Bloemer, J., \& Knuepfer, E. (2019). Valuing Biodiversity in Life Cycle Impact Assessment. Sustainability, 2019(11), 5628. https://doi. org/10.3390/su11205628

4. Directive (EU) 2018/2001 Of the European Parliament and of the Council of 11 December 2018 on the promotion of the use of energy from renewable sources (recast), Official Journal of the European Union, L 328/82.

5. Brunner, P. H. (2010). Substance flow analysis as a decision support tool for phosphorus management. Journal of Industrial Ecology, 14(6), 870-873.

6. Killiches, F. (2013). Phosphat - Mineralischer Rohstoff und unverzichtbarer Nährstoff für die Ernährungssicherheit weltweit. Bundesanstalt für Geowissenschaften und Rohstoffe, Hannover, Germany.

7. USGS. (2008). Mineral commodity summaries 2008. In U.S. Geological survey, mineral commodity summaries. U.S. Geological Survey (USGS), Reston, VA.

8. Gwosdz, W., Röhling, S., \& Lorenz, W. (2006). Bewertungskriterien für Industrieminerale, Steine und Erden. Geologisches Jahrbuch 12/2006, Reihe H, Wirtschaftsgeologie, Berichte zur Rohstoffwirtschaft Hannover, Germany.

9. Pinnekamp, J., Everding, W., Gethke, K., Montag, D., Winfurtner, K., Sartorius, C., Von Horn, J., Tettenborn, F., Gäth, S., Waida, C., Fehrenbach, H., Reinhardt, J. (2011): Phosphorrecycling Ökologische und wirtschaftliche Bewertung verschiedener Verfahren und Entwicklung eines strategischen Verwertungskonzepts für Deutschland.

10. Spörri, A., Erny, I., Hermann, L., \& Hermann, R. (2017). Beurteilung von Technologien zur Phosphor-Rückgewinnung. Ernst Basler + Partner AG.

11. Cordell, D., Drangert, J.-O., \& White, S. (2009). The story of phosphorus: Global food security and food for thought. Global Environmental Change, 19(2), 292-305.

12. van Kauwenbergh, S. (2010). World Phosphate Rock. In Technical Bulletin IFDC. International Fertilizer Development Center (IFDC).

13. Vaccari, D. A., \& Strigul, N. (2011). Extrapolating phosphorus production to estimate resource reserves. Chemosphere, 84(6), 792-797.

14. van Vuuren, D. P., Bouwman, A. F., \& Beusen, A. H. W. (2010). Phosphorus demand for the 1970-2100 period: A scenario analysis of resource depletion. Global Environmental Change, 20(3), 428-439.

15. United Nations. (2017). World population prospects: The 2017 revision, key findings and advance tables (Working paper no. ESA/P/WP/248). United Nations, Department of Economic and Social Affairs, Population Division.

16. Reinhardt, G., Rettenmaier, H., \& Vogt, R. (2019). Establishment of the indicator for accounting of the resource "phosphate" in environmental assessments. ifeu papers 01/2019, available at www.ifeu.de/en/ifeu-papers/. ifeu - Institute for Energy and Environmental Research Heidelberg.

17. Patyk, A., \& Reinhardt, G. A. (1997). Düngemittel - Energie- und Stoffstrombilanzen. Friedr. Vieweg \& Sohn Verlagsgesellschaft mbH.

18. Fehrenbach, H. (2014). ILUC und Nachhaltigkeitszertifizierung -(Un-)Vereinbarkeit, bleibende Lücken, Chancen. [ILUC and sustainability certification - (in)compatibility, remaining gaps, opportunities.] In: Biokraftstoffe zwischen Sackgasse und Energiewende - Sozial-ökologische und tansnationale Perspektiven, oekom Verlag, Munich.

19. Finkbeiner, M. (2013). Indirekte Landnutzungsänderungen in Ökobilanzen - wissenschaftliche Belastbarkeit und Übereinstimmung mit internationalen Standards. [Indirect land use change in life cycle assessments - scientific robustness and consistency with international standards.] Study commissioned by OVID and UDB, Berlin. 
Open Access This chapter is licensed under the terms of the Creative Commons Attribution 4.0 International License (http://creativecommons.org/licenses/by/4.0/), which permits use, sharing, adaptation, distribution and reproduction in any medium or format, as long as you give appropriate credit to the original author(s) and the source, provide a link to the Creative Commons license and indicate if changes were made.

The images or other third party material in this chapter are included in the chapter's Creative Commons license, unless indicated otherwise in a credit line to the material. If material is not included in the chapter's Creative Commons license and your intended use is not permitted by statutory regulation or exceeds the permitted use, you will need to obtain permission directly from the copyright holder.

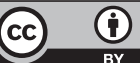

